\title{
UNWILLINGNESS TO PAY FOR URBAN WATER DEVELOPMENT IN THE CAPE COAST MUNICIPALITY OF THE CENTRAL REGION OF GHANA
}

\author{
Mr. M. K. Nkrumah ${ }^{9}$
}

\section{Abstract}

Unwillingness to pay (UNWTP) findings have been ignored in a number of willingness to pay studies. UNWTP explains the limited access to potable water by many households in the Cape Coast Municipality. Among the reasons given for . UNWTP, $70 \%$ of the sampled households mentioned the high level of water price as the main reason for UNWTP. It also addresses gender implications on payment of utility services at the household level. Men rather than women are more unwilling to pay, giving support to the current debate on empowerment of women to give financial support at the household level. UNWTP was finally identified as a strong indicator of consumers' dissatisfaction with the services of the water company. Improvements in the quality of services by the water company to customers and the government support for the poor by way of subsidies are likely to increase access to potable water by the people, especially the poor.

\section{Introduction}

Access to potable water is essential for good human health, in particular and the development of socio-economic activities in general. To draw attention to the need for safe water and sanitation, the UN declared the 1980 s as the International Water and Sanitation Decade (IDWSD). It was anticipated that guaranteeing reasonable access to safe water to all inhabitants of the world by 1990 would be followed by significant improvements in health and social conditions (Poppel \& Heijden, 1997). However, by the end of the water decade, majority of the people, especially in the developing countries, had limited or no access to potable water (World Bank, 1998/99). Currently, 1.2 billion people worldwide are without access to potable water (WASH, 2002). Millions of deaths worldwide every year are directly attributable to water-borne diseases such as diarrhoea, which constitute a worldwide silent killer (WASH, 2002).

${ }^{9}$ Lecturer in the Dept of Environmental Resource Studies 
Access to safe water in urban areas varies by socio-economic status of households. In 1991/92, 23 percent of the very poor and 42 percent of the non-poor in urban areas in Ghana had access to potable water. By $1998 / 99$ these proportions had reduced to 8.3 percent for the very poor and 36.5 percent for the non-poor (Ghana Statistical Services, 1998/99). But the proportion of the very poor, which used natural sources of water, increased from 21.2 percent in $1991 / 92$ to 24 percent in 1998/99. The picture is one of declining access to safe drinking water to the majority of Ghanaians, especially the very poor in the 1990s. This may be related to the inability of the people to pay for potable water due to increases in the tariff levels. Nonetheless, the shift in the proportion using pipe- borne water to other sources of water has implications for the health and economic conditions of the people.

It has been argued that a rise in water tariffs to, at least cover the cost of water delivery would increase efficiency and equity,and make potable water more available to many people in Ghana.To ensure water availability the Ghana Water Company ( GWCL) has proposed privatization of urban water systems while the rural water systems are managed by the Community Water and Sanitation Agency. It is intended that the urban population can afford and will be willing to pay for potable water without recourse to thorough willingness-topay (WTP) studies. Many studies have been carried out worldwide on consumers WTP(World Bank,1993; Whittington et al. 1991; Ghana Urban Water Study, 1999).

However, not much attention has been paid to unwillingness- to -pay by households for improvement in potable water supply. The paper contributes to discussions generally on WTP, examines reasons why some consumers are UNWTP and analyzes the policy implications of the findings.

The paper analyses consumers' unwillingness to pay (UNWTP) for improvement in water supply using data from the Cape Coast Municipality in Ghana.The results present policy implications for effective urban water-demand management. It is structured into six sections. Section one gives a brief introduction while the second describes the context of the study. Sections three and four discuss 
the urban area under study and methodology respectively. Section five examines the main findings of the study. The final section presents the policy implications of the main findings of the study.

\section{Contextualization of the Study}

The theoretical framework underlying the utilization of water is polarized: potable water as a free/public good or as a private/economic good (World Bank,1994 ; Briscoe et. al, 1990; Morris and Perry-Jones,1997). These changes stem from the way people in different societies or places value potable water. Available literature shows that three distinct worldviews have been predominant in the way people value water ( McNiel 2000, cited in Bacho,2001). Peoples' perception of the value of potable water as a free gift of nature has changed to that as a social good and now as an economic good. However, in most developing countries, conception ofpotable water as an economic good is mixed.

First, its innate quality makes water an important part of the human existence. Water is part of nature and part of all aspects of human existence. Secondly, its fulfilment of the natural needs /basic needs of humans and other living things gives the general impression that it is a natural gift of nature and should not be paid for. The adherents of this view lose sight of the opportunity cost in terms of time spent in fetching water by households. It is this failure to factor in the economic value of time and labour that blurs the actual value of water beyond its intrinsic value. While the objection to the provision of water to the people should not be based entirely on economic principles, the problem still remains as to how to meet the cost of providing this resource free to the poor. While the poor consumers may not be paying for water produced by the state directly, they do pay indirectly through the payment of taxes.

The proclamation that water should be treated as an economic good originated at the Dublin Conference in 1992. Proponents of water as a private good argue that water should be priced at its economic or marginal cost level to cover cost and investment (Choe and Varley, 1997). Proponents of potable water as a private good contend that potable water is just like any other good, that its production and allocation should be determined by the overriding 
value of consumer's sovereignty, that is, by the amount that people are willing, and able to pay for. The criterion of consumer's sovereignty totally ignores the distribution of income in society. If the poor cannot pay as much for a unit of water as the rich they should get less water, even if the marginal value to them in terms of other values (or utility) is greater.

From the above discussions it is clear that potable water is neither a purely social nor a purely economic good especially in the contemporary developing countries. This situation has thus generated a lot of arguments on the pricing of water. The argument among many consumers is that they cannot pay economic tariff because majority of the people are poor as a result of high unemployment level in the country. Thus, for equity and social reasons, the economic package needs to be modified. It is therefore argued that social and equity dimensions of pricing water are considered alongside the economic framework. This decision must be supported by empirical data, hence the rationale for the WTP research.

\subsection{The Urban Area Covered by the Study}

The Cape Coast Municipality is one of the municipalities created in the country in 1992. The Municipality, the smallest in the Central Region, has an area of 122 square kilometers. The Municipal capital, Cape Coast, is also the Central Regional Capital.

The Kakum river and its main tributaries, Nkyemna and Kyekyewere, drain Cape Coast Municipality. Apart from the Kakum river, most minor streams end in wetlands, the largest being the Fosu Lagoon at Bakaano (see Fig. 1). 


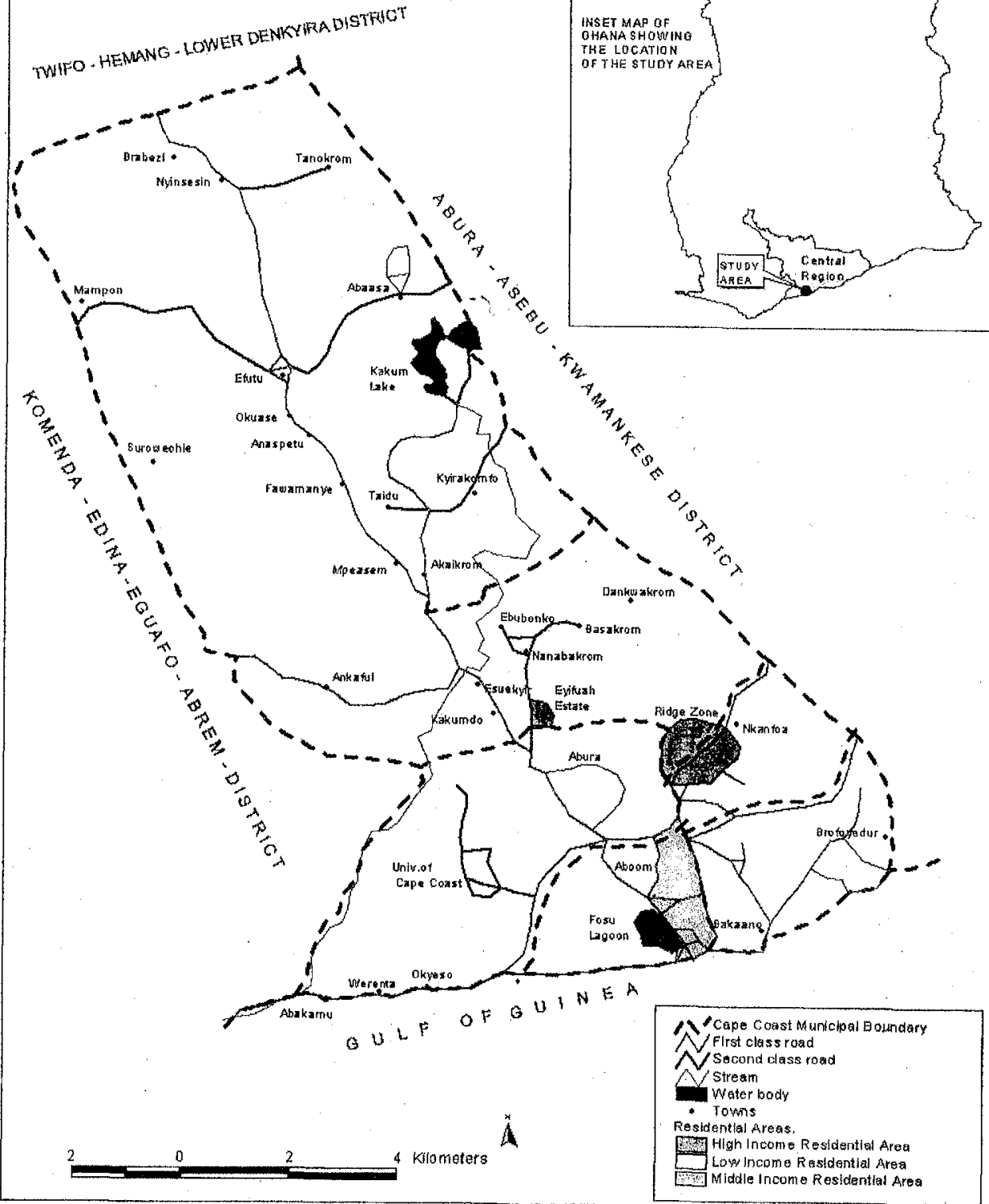


The provision of potable water to meet the demands of the people in the municipality dates back to 1928 at Brimsu (GWSC,1997), when the first pipe was commissioned. The Ghana Water Company Limited (GWCL) produces about 16 million $\mathrm{m}^{3}$ (3.5 million gallons) of water a day to serve the municipality and other surrounding towns and villages. About 77 percent of the people in the municipality are served with pipe borne water from the Brimsu Waterworks. The remaining 23 percent depend on rivers, wells, bore holes and rain harvesting as their main sources of drinking water (Ghana Statistical Service, 1995).

The Kakum River is unable to provide enough water throughout the year as a result of the seasonal distribution of rainfall in the basin. The total annual rainfall in the Kakum basin is generally low, about $1087 \mathrm{~mm}$. The main rainy season starts from March to June with the peak in June and the minor one from September to October (Dickson and Benneh, 1988). November to February are generally dry months. Temperatures are generally high throughout the year. The mean annual temperature is about $26^{\circ} \mathrm{C}$ with little seasonal variation. The mean annual evapotranspiration rate is also generally high, about $1396 \mathrm{~mm}$ and affects the water balance, especially in the dry season. The mean annual relative humidity does not exceed 75 percent (Dickson and Benneh,1988).

The vegetation of the municipality falls within two major vegetation types, the southern marginal vegetation type (SM) is to the south and the dry semi-deciduous type to the northwest (Dickson and Benneh, 1988). Floristically, it is dominated by Antiaris and Chlorophora species. It is composed of other woody plants with thick barks. The original vegetation of dense scrub has been replaced by secondary vegetation as a result of human activities, such as farming, bush fires, logging and charcoal burning. The deforestation of the vegetation, especially at the headwaters of the Kakum river has implication for water development in the area.

The population of the municipality in 2000 was 119,340 (Ghana Statistical Service, 2000). Cape Coast Municipality experienced modest population increase in the $1990 \mathrm{~s}$, resulting in an intercensal growth rate of 2.1 percent between 1984 and 2000 (Ghana Statistical 
Services, 2000). This modest growth rate of the population in the municipality may be related to government policy on family planning, education and tourism development in the country. Cape Coast has traditionally enjoyed and continues to enjoy the status of being the seat of education in Ghana. In 1993/94, the total enrolment in all educational institutions in the municipality was about 12000 , which increased to 16,000 in $1996 / 97$ academic year (personal discussion with the Regional Education Officer, Cape Coast). Most of these institutions have facilities that rely on water for their effective functioning. The expected increase in the level of population in the municipality is likely to exert severe pressure on water supply.

Despite the general deterioration of economic activities in Cape Coast, efforts have been made to generate employment and business activities within the municipality since the 1990s. Cape Coast has a few large scale and medium scale industries; which include the Ameen Shangari Soap Making and Brake Lining Plants, the Pan Sawmills and the Cape Coast Stone Quarry. Medium scale industries include distilleries, soft drink manufacturing, building and road construction, block making and mineral water production. Currently, except for the sawmills and the stone quarry, the rest of the industry is on the decline (Consortium, 1994).

In an attempt to improve upon the general public health situation in Cape Coast, the colonial government established an infant welfare clinic in Cape Coast in 1928. Between 1983 and 1994 Cape Coast witnessed a rapid increase in health establishments, mainly private clinics that offer alternative services as a result of the deteriorating conditions in the government health sector. By 2001, there were about 31 hospitals/clinics in the municipality, 5 of which are government hospitals. These health facilities also use water. Therefore, shortage of potable water at the hospitals will adversely affect the effective functioning of the hospitals and clinics in the municipality. It was therefore expected that consumers would be willing to pay for improvement in the water supply in the municipality. 


\section{Methodology}

The primary data for the study was part of a Contingent Valuation(CVM) study on willingness to pay for improvement in urban water supply and its utilization in the Cape Coast Municipality collected between January and March, 2000.The Contigent Valuation Methodology (CVM) was originally developed as a tool for environmental economics in the 1980s and has now been adopted in most social science research (MWH,1999; Kendie,1996; World Bank Water Team,1993; Mithel and Carlson,1989). The CVM involves asking respondents their willingness to pay for a commodity and at what price they will be willing to pay, using bidding game experiments (Mitchel and Carlson,1989). The CV questionnaire consists of three parts: a description of the good being valued; two, consumers WTP and three questions about respondents' background characteristics.

In order to determine the socio- economic characteristics of the household which influence willingness to pay, each household is characterised by the vector of socio-economic characteristics, $\mathrm{Z}$ and the vector of the characteristics of the improved water delivery system which is specific to the household, correspond to vector of the household is denoted as $X$, whereas the characteristics of the non-improved system is $Y$. Then the utility of household, $i$ in each of the two cases is given by:

$$
\begin{aligned}
& \mathrm{Ui}=\mathrm{U}_{1}\left(\mathrm{Z}_{1} \mathrm{X}\right) \\
& \mathrm{Ui}=\mathrm{U}_{2}\left(\mathrm{Z}_{1} \mathrm{Y}\right)
\end{aligned}
$$

Then the household $i$ will choose and be willing to pay for improved potable water delivery if $U_{1}\left(Z_{1} X_{1}, e_{1}\right)>U_{2}\left(Z_{1} Y_{1} e_{2}\right)$.

Suppose a variable $\mathrm{W}$ that captures willingness to pay behavior is defined as in (3):

$\mathrm{Wi}=\{1$, if household $\mathrm{I}$ is willing to pay for improved water delivery; 0 , otherwise

Then the probability that household $\mathrm{i}$ is willing to pay $\operatorname{Prob}(\mathrm{Wi}=1)$ is given by (4): $\operatorname{Prob}(W i=1)=\operatorname{Prob}\left(\left(U_{1}\left(Z_{1} X_{1} e_{1}\right)>U_{2}\left(Z_{1} Y_{1} e_{2}\right)\right)\right.$

The total number of respondents interviewed was 470 domestic consumers. For the purposes of sampling, the stratified sampling 
procedure was used to classify the municipality into two socioeconomic zones (high-income and low-income). The rationale for the adoption of income as a basis for the stratified sampling design is based on the premise that income of the consumer influences the ability to pay and the socio-economic characteristics of the locality influence the supply of basic water infrastructure. While highincome localities such as the Ridge have better infrastructure for in house water supply, the poor and low-income localities such as Abura village have limited water infrastructure. Secondly, the socioeconomic approach has been used in three separate studies in Cape Coast by Hinderink and Sterkenburg in 1975; Owusu and Blankson in 1976 and Agyei-Mensah in 1997. In all the studies the Ridge stands out clearly as a high -income locality while Abura, on the other hand, comes out as a severèly deprived area, having one of the lowest average income levels.

The households in the municipality were grouped into 19 zones based on socio-economic characteristics of each zone. These comprised of five high-income localities and fourteen low-income localities. Nine out of the nineteen localities, representing about 47 percent of the total population were randomly sampled for the study. In each of the socio-economic groups, the simple random technique was used to select the localities for the study. The high-income localities sampled were the Ridge locality and Eyifuah Estate. The Ridges were made up of the first, second, third, and fourth. Most of the residents were top civil servants, professionals and lecturers in the high-income bracket. The low-income localities sampled for the study included Brofoyedur and Abura villages. Generally, the houses were not well planned and had limited basic water infrastructure and toilet facilities. The main source of water was the public standpipe, which was limited in number in relation to the number of people they served. Most of the houses were compound houses. These provided shelter for mostly family members and workers, usually in the junior positions in the civil service and other self-employed organisations. Sanitation in the low-income localities was generally poor. Most houses lacked modern toilet facilities. 
The Multinomial Logit Model and Ordinary Least Squares (OLS) were used to analyze the factors, which influenced the respondent's WTP and WTP bids. The main dependent variables were WTP and WTP bids. Respondents were asked to indicate whether they were willing to pay in principle a little more money for improvement in water supply in Cape Coast Municipality and if yes, how much money they were willing to pay. The multinomial logit model was used to analyze the WTP because it was dichotomous with two possible outcomes namely one (1) for yes or zero (0) for No. The Logit model was used to analyze the WTP bids because it was continuous in nature.

\section{Results of the Study}

\section{WTP for improvement in the water supply}

The respondents were asked whether they would be willing to pay for a particular improvement in services. Households were asked to indicate whether they would be willing, in principle, to pay a little more money for improvement in water supply in the Municipality. About seventy-three percent (73) of the respondents agreed to pay in principle, while about twenty-seven percent $(27 \%)$ did not agree to pay at all.

\section{Unwillingness to pay (UNWTP)}

About twenty-seven percent $(27 \%)$ of the sampled population reported that they could not pay any additional money for the improvement of the water supply in the Municipality. When the result was further analyzed by locality and gender the following results presented in Table 1 emerged :

Table 1: UNWTP by Income-group and Gender

\begin{tabular}{|l|c|c|c|c|}
\hline Income-Group & $\begin{array}{c}\text { Total } \\
\text { Number }\end{array}$ & $\begin{array}{c}\text { Number of } \\
\text { respondents } \\
\text { UNWTP }\end{array}$ & $\begin{array}{c}\text { Number of } \\
\text { Males UNWTP }\end{array}$ & $\begin{array}{c}\text { Number of } \\
\text { Females UNWTP }\end{array}$ \\
\hline High-Income & 74 & 10 & 1 & 0 \\
\hline Low-Income & 346 & 117 & 100 & 17 \\
\hline Total & 470 & 127 & 101 & 26 \\
\hline
\end{tabular}

Source: Field work,2000 
About seven-seven percent (27\%) out of four hundred and seventy (470) respondents reported that they were not willing to pay for improvement in the water supply (Table 1). Majority of the UNWTP households, about sevent-four percent (74\%) were from the lowincome localities. Futher analysis of the respondents who reported that they were not willing to pay, about eighty percent $(80 \%)$ of them were males (Table 1). Thus, there was a clear gender dimension with respect to un willingness to pay for water development in the Cape Coast Municipality. The main reasons reported by the consumers are reported in Table 2.

Table 2: Percentage distribution of respondents according to reasons for UNWTP

\begin{tabular}{|l|c|c|}
\hline \multicolumn{1}{|c|}{ Reasons } & No, of respondents & \% of respondents \\
\hline Current charge very high & 64 & 70.3 \\
\hline Unemployed & 16 & 17.6 \\
\hline Government should pay & 3 & 3.3 \\
\hline $\begin{array}{l}\text { Mismanagement of resources } \\
\text { by GWCL staff }\end{array}$ & 8 & 8.8 \\
\hline Total & 91 & 100 \\
\hline
\end{tabular}

Source: Field work,2000.

The main reason given by respondents for unwillingness to pay is the high cost of pipe- borne water (Table 2). About seventy percent $(70 \%)$ of the respondents mentioned the high price of water as the main reason for UNWTP. On the other hand, eighteen percent $(18 \%)$ of the respondents indicated that they were unemployed and another three percent $(3 \%)$ felt that it was the responsibility of the government to pay for water and give it free of charge to the people.

\section{Discussion}

One major constraint facing water demand by households in Cape Coast Municipality and in most developing countries is the high 
level of poverty. The poverty level in the study area is defined as those households who have per capita expenditure of less than $ф 40$ 000 per month or $\$ 480000$ per annum. The increase in the incidence of urban poverty in Cape Coast Municipality points to increasing poverty in the country in particular and in most developing countries in general. The central developmental issue in most developing countries is the widespread poverty, on one hand, and rapidly growing population, on the other hand (Bacho, 2001). The two issues have resulted in low access to potable water by households in most developing countries. At the individual and household levels poverty manifests itself in very low incomes. According to the World Bank (2000), cited in Bacho (2001), at the start of this century, of the world's 6 billion people, 2.8 billion live on less than $\$ 2$ a day and 1.2 million on less than $\$ 1$ a day. Poverty is also evident in poor people's extreme vulnerability to ill health, low access to utility services, economic dislocation, personal violence and natural disasters. At a Water Conference on Africa in Accra in 2002, a communique issued indicated that on the average over sixty percent $(60 \%)$ of the population who fall within the lowincome bracket and who live in densely populated urban areas have the least access to potable water. Furthermore, they pay more than 10 times the official rates to vendors for water supply (Public Agenda, 2002). However, the poor are willing to pay for improvement in water supply but are constrained by poverty. Ability to pay for utilities is weak, especially for the poor. Hence, attempts to price potable water solely on economic basis is likely to backfire and make the government unpopular. One choice is to dialogue and give the poor some form of subsidy.

At the national level, poverty in Sub- Saharan Africa is manifested by the growing external debt burden. Between 1980 and 1997 the external debt of sub- Saharan African countries increased by nearly threefold. Ghana's external debt within the period stood at $\$ 3,800$ million ( $\$ 26.6$ billion), with a debt service ratio of 24.3 percent (Ghana Government, 1992, cited in Bacho, 2001).Consequently most governments in developing countries 
invest less in infrastructural developments or seek external funding to finance these projects. The bulk of the countries facing acute poverty are in sub-Saharan African countries and South Asia. All the last five countries on the United Nations Human Development Index are in sub-Saharan Africa (Bacho, 2001). As these countries enter the 21 st century, the main challenge will be to reduce the level of poverty so that consumers would have enough money to increase access to potable water.

Various social policies implemented in most developing countries by the governments to support the poor to have access to potable water have been unsatisfactory. The lessons gained after the World Bank International Water and Sanitation Decade (IWSD) (1980-90) in many developing countries is that many of the poor remained unserved because free water was equal to no service. Second, the payment of subsidy through the life line structure (the minimum price, which is subsidized) in the increasing block tariff (IBT) makes the price paid by the poor regressive. The tariff structue for the Ghana Water compay uses the Increasing Block Design (IBT); that is, the initial price charged for the first cubic meter of water consumption is very low because of the built-in subsidy for consumers. Additional water consumption above the first $\mathrm{m}^{3}$ attracts higher tariff. The assumption of the IBT structure is that most consumers, especially the poor are not likely to consume more or above 1000 litres $\left(\mathrm{m}^{3}\right)$ and consequently pay less.

The IBT structure being used in Ghana and many developing countries has not benefitted the poor. The IBT structure favours the rich consumers because it is heavily subsidized and connected, while the poor pays very high prices for water because he/she generally buys the water from stand pipes. About seventy percent $(70 \%)$ of the sampled households in the Cape Coast Municipality indicated that they cannot pay because the current price per cubic meter is very high. As such, they could not pay any additional money for improvement in water supply. Tariff setting in most developing countries do not reflect the ability and WTP concepts and may be regressive from the point of view of impact on the poor (Kendic, 1996). Whittington, Lauria, and $\mathrm{Mu},(1991)$ carried out 
WTP studies in Onitsha, Nigeria and concluded that fifty-eight percent $(58 \%)$ of the sampled population were paying eighteen percent $(18 \%)$ of their income on water in the dry season. That study supported the argument that the poor pays more for water

Water utility officials and other experts tend to make several arguments in support of IBT structure (Boland and Whittington, 2000). First, some of them claim that IBTs promote equity by forcing wealthy households to cross-subsidize the water usage of the poor households. The argument assumes that all households have private- metered connections and that wealthy households use more water than poor households because water is a normal good and increases with income. For example, high-income consumers have gardens to tend, cars to wash, and appliances that use water. Because a greater percentage of their water use occurs in the higher blocks, they pay a higher average price in the initial block. Second, IBT advocates contend that charging commercial customers a higher rate than domestic consumers, also promotes equity. The rate structure enables the utility company to cross-subsidize poor domestic consumers. Third, they argue that IBTs promote conservation and sustainable water use. That is, because in the highest block, tariffs can be made punitively high, and thus discourage wasteful water use. Other advantages of IBTs include implementation of marginal cost pricing and public health externalities.

Survey findings from many developing countries support the assertion that IBTs rather support the rich while the poor rather pays higher tariffs or denied access altogether, simply because they are excluded from the main distribution system or share meters in compound houses. One literature has noted that IBTs can only work as their proponents advocate if each household (rich and poor) has a private, metered- water connection (Boland \& Whittington, 2000). Yet, many cities and towns in developing countries do not meet this condition. Private metered -water connections are often available to high-income households, the poor must obtain water from shared connection; neighbour's source, water vendors or stand pipes. If several households share a metered connection and an IBT is in 
effect, water used by the group quickly exceeds the volume in the initial block, pushing water used into higher price blocks. Thus, the IBT will have the opposite effect from its intent: the poor will pay higher average price for water than the rich.

There are suggestions that subsidies should be explicit and clearly targeted at the poor (Yapes, 1999; Boland \& Whittington, 2000; Alfaro, 1996). That is, the subsidies should be removed from the tariff structure so that all consumers pay the same tariff for the quantity of water consumed. By implication, the IBT would be repaced with uniform tariff; that is, you pay less if you consume less and vice versa. Uniform price as against IBT has a number of advantages, among them, each unit is charged at the same level so bills are simple to calculate, transparent and easily understood by customers. The single volumetric charging structure could be considered to be equitale. This is, because all customers face the same tariff, bills only vary according to volume consumed. However, it tends to be regressive. If all customers are charged the same for each unit of water consumption, low-income households spend a higher proportion of their income on water than the rich households. To address this effect on the poor, subsidy is targeted at the poor and paid on their behalf through the national and municipal budgets to the water company. In this case, the utility company receives the same revenue for the same volume of water whether consumers are poor or wealthy because the tariff is not discriminatory (Yapes, 1999). The only issue is the reliability of the register of poor people and the honesty and intergrity of the officials who would be charged with the responsibility of administering the programme. The periodic national surveys on living standards and housing census in Ghana could form a good basis for implementing such a policy in the country. Targetted subsidy will require the political will of the government in most developing countries to implement. Access to potable water is a social right and has a lot of positive externalities for the country. Poverty is high and increasing in most urban areas as a result of growing unemployment. If the health of the peolpe is considered as a national priority money would have to be found to support the poor while the rich pays economic tariffs to support the 
water company. The proportion of monthly income spent on water is higher among low-income households compared to high income households. This partly explains why the poor are less willing to pay for improvement in water supply.

Kendie (1996) concluded from a study of water utilization among women in Northern Ghana that the low willingness to pay was due to the fact that the responsibility for the payment of the tariff rested with the women - the poorest segment of the society. This finding was also observed in the Cape Coast study. In South Africa, as elsewhere in the developing world, women are the primary care-givers and home makers, and hence the benefits of infrastructure service delivery are disproportionately felt by women (Bassett et al. 1992 cited in Bond, 1999). The element of time saving from improved infrastructure is also important, particularly to women. Time saving due to the nearness and availability of an improved water source has been reported to lead to more time not only for child care, including breastfeeding and better food preparation, but also for agricultural or income generation activities which could result in better family health (Bond, 1999).

In urban centers in developing countries, women use water to make ice cream, drinks, snacks, and other small-scale products, which are then sold to raise cash income to purchase clothes, medicine, and other domestic necessities. For, both in urban and rural areas, they are responsible for family welfare. Increasingly, women have to provide for all necessities of their children and elderly. A gender division of labour exists in most households studied and other parts of the country. The social norm is for women to do the unpaid physical work and the men to pay the bills (rent, electricity bills, water bills and school fees) and provide maintenance money (Songsore \& McGranahan, 1996). While it is becoming the general practice for women to help in the payment of the bills on behalf of impecunious male heads of households, very few men help in performing the routine household chores on behalf of overworked women. Women and children who are responsible for water collection and its use for laundry, cooking and domestic hygiene, 
suffer most if supplies are difficult to obtain are therefore more willing to pay for water at any cost.

\section{Conclusion}

Water is a basic neccesity of life and there is no close substitute. However, though only a relatively small percentage of the sampled population were unwilling to pay the findings of the study have policy implications. One, poverty was identified as one of the main reasons for UNWTP. Poverty allevation stategies, such as creation of jobs will improve the financial position of consumers so that they would be able to pay economic tariff for potable water. Two, the observed high price of potable water stems from the built-in subsidy and the IBT structure. It is recommended that the IBT structure be abolished and replaced with simple volumetric tariff or uniform tariff so that all consumers face the same tariff, irrespective of the economic status. Consequently, the tariff for the poor will be regressive, and they could be supported with a direct subsidy by the government by paying the money directly to the Water Company on their behalf. This policy will require a register of the poor consumers in a locality. UNWTP also stems from the poor services consumers receive from the Water Company. Improvement in the quality of services by the Water Company to consumers (regular and good quality supply) will entice consumers to be more WTP for improvement in their services. The District Assemblies could be called upon to support the communities by using a portion of their Common Fund to expand and extend water infrastructure to areas not covered by the sevice lines of the company. The creation of Water Fund by the government could serve as a common fund, from which monies would be withdrawn to pay subsidies to the poor and other water -related issues. Finally, in reviewing tariff for water, WTP studies should be part of the process, so that a more realist tariff levels would be set. 


\section{References}

Bacho, F. Z. L. (2001) From a Gift of Nature to an Economic Good: Changing Perceptions and Management of Drinking Water. Spring Research Series No 35.

Boland, J. \& D. Whittington (2000). The Political Economy of Water Tariff Design in Developing countries: Increasing Block Tariffs versus Uniform Price with Rebate (215-237). In Ariel Dinar (ed.). The Political Economy of Water Pricing Reforms.

Bond, P. (1999). Basic Infrastructure for Socio economic Development, Environmental Protection and Geographical Desegregation. South Africa's Unmet Challenge. Geoforum (30). pp 43-59.

Briscoe, J.;P. F. deCastro; C. Griffin; J. North \& O. Olsen (1990).'Towards Equitable and Sustainable Rural Water Supplies: A Contingent Valuation in Brazil." The World Bank Economic Review (4), 2. pp 115-134.

Choe, K. A.C. \& R. C. G. Varley (1997), Conservation and Pricing: Does Raising Tariffs to An Economic Level for Water make people Worse Off? Water Management Practice for Water Conservation Workshop, 7-10 September, 1997. South Africa [online]. Available: http//www.Africanwater.org.html

Consortium-CIHSD (1994). Cape Coast - Elmina Structure Plan Report No.1 - The Existing Context (Database). Cape Coast Municipal Assembly, KEEADistrict Assembly, Regional Co-Ordinating Council (CEDECOM).).

Dickson K.B. \& G. Benneh. (1988). A New Geography of Ghana. London. Longman Group Ltd.

Ghana Statistical Service. (2000). Ghana Living Standards Survey Report of the Fourth Round GLSS 4. Accra; Statistical Service.

GWSC (1987) .Water Supply Extensions: Cape Coast and Sekondi-Takoradi Population, Water Demand and Hydraulic Review. Unpublished report by IGIP Consulting Engineers. September, 1987.

Kendie, S.B. (1996). Some Factors Influencing Effective Utilization of Drinking Water Facilities: Women, Income, and Health in Rural North Ghana. Environmental Management (20): 1. pp1-10.

McPhail, A.A. (1993). The Five Percent Rule for Improved Water Services. Can Households Afford More? World Development (21), pp 963-973.

MWH. (1999). Ghana Urban Water Supply and Ability to Pay, Demand Assessment 
and Tariff Structure Study. Accra, Ghana: London Economics in Association with John Young

Mitchel R.C. \& R.T. Carson (1989). Using Surveys to Value Public Goods. Washington, DC: The Contingent Valuation Method.

Poppel, F. van \& C. van der Heijden. (1997). The Effects of Water Supply on Infant and Childhood Mortality: A Review of Historical Evidence. Health Transition Review( 7), pp 113-148.

Public Agenda ( 2002). Water and Sustainable Development in Africa. Regional Stakeholders Conference for Priority Setting. An International Water Conference held in Accra,15-17 April,2002.

Rogerson, C. M. (1996). Willingness-To -Pay for Water. The International Debates. Water S.A. (22): 2. pp 373-380.

Regional Education Office, (2000): Educational Statistics. Unpublished report of the Central Office of the Ghana Education Service.

Songsore, J. \& G. McGranahan. (1996). Women and Household Environmental Care in GAMA, Ghana. Stockholm Environment Institute in Collaboration with Sida. Stockholm, Sweden.

WASH (2002). WSSCC and UN-Habitat Call for Urgent Action to Address Water and Sanitation Crisis. Roundtable Panel Discussion at CDS Prep ComII: From Bonn to Johannesburg: Putting Water and Sanitation on Top of the Political Agenda. Press Release, 29 January 2002.

Whittington D.; D.T. Laura \& X. Mu (1991). A Study of Water Vending and Willingness to Pay for Water in Onitsa, Nigeria. World Development(19): 2-3 pp179-198.

World Bank. (1993). 'The Demand For Water in Rural Areas: Determinants and Policy Implications. The World Bank Research Observer( 8) No 1 pp 47-70.

World Bank. (1999). 1998/99 World Development Report. Washington, DC: The World Bank

Yapees, G. (1999). Do Cross/ Subsidies Help the Poor to Benefit from Water and Wastewater Services: Lessons from Guayaquil. Unpublished UNDP/World Bank WSP working paper series[online].

Available http// www.undp.org.html. 